\title{
HuMANIZAÇÃO, DIGNIDADE, \\ IGUALDADE, LIBERDADE, RESPEITO E \\ TOLERÂNCIA: DIREITOS HUMANOS \\ COMO CONTEÚDO DE SOCIOLOGIA \\ NO ENSINO MÉDIO
}

Elisabeth da Fonseca Guimarães ${ }^{1}$

\begin{abstract}
Resumo
Os termos humanização, dignidade, igualdade, respeito, liberdade e tolerância são incorporados a linguagem dos estudantes de modo estandardizado. Estampados em camisetas e cartazes, assumem uma variedade de significados de acordo com o favorecimento das circunstâncias. 0 objetivo deste artigo é trabalhar o significado sociológico de cada concepção, tendo em vista a inserção do tema direitos humanos como conteúdo de Sociologia no nível médio. A experiência docente de professores da disciplina do Distrito Federal e da cidade de Uberlândia se insere na análise, a partir de depoimentos que ajudam a refletir sobre a contribuição dessas concepções como conteúdo de Sociologia.
\end{abstract}

Palavras-chave: Declaração Universal dos Direitos Humanos. Ensino de Sociologia. Ensino Médio. Experiência docente.

\footnotetext{
${ }^{1}$ Bolsista do CNPq de pós-doutorado em Sociologia da UnB; doutora e mestre em Educação pela Unicamp; professora do departamento de Ciências Sociais da Universidade Federal de Uberlândia -MG. End. eletrônico: elisabeth@ufu.br
} 


\section{HUMANIZATION, DIGNITY, EQUALITY, FREEDOM, RESPECT AND TOLERANCE: HUMAN RIGHTS AS SOCIOLOGY CONTENT IN HIGH SCHOOL AbSTRACT}

The terms humanization, dignity, equality, respect, freedom, and tolerance are embedded into the student's language in a standardized manner. Printed in T-shirts and posters, they take on a variety of meanings depending on the circumstances. The purpose of this article is to show the sociologic meaning of each term, having in mind the introduction of the human rights topic as Sociology content in high school. The teaching experiences of teachers of this discipline in Brazil's Federal District and in the city of Uberlandia (located in Brazil) are analyzed, based on testimonies that help reflect on the contribution of these terms as Sociology content.

Keywords: Universal Declaration of Human Rights. Teaching sociology. High school. Teaching experience.

\section{INTRODUÇÃO}

$\mathrm{E}$ ste artigo faz parte de um estudo mais amplo que propõe inserir os direitos humanos como conteúdo da disciplina Sociologia no nível médio. Concentra-se na análise de termos e concepções expressos na Declaração Universal dos Direitos do Homem, daqui para frente DUDH². São eles humanização, dignidade, igualdade, liberdade, respeito e tolerância. 0 esclarecimento sobre a construção histórica, social e pedagógica de cada um dos termos selecionados, não significa que apenas eles sejam importantes ou que se apresentem isolados na realidade. Pelo contrário, tanto no próprio texto da DUDH como em situações reais da experiência humana, estão estreitamente vinculados. Não há como trabalhar a dignidade separada da humanidade e do respeito; a igualdade desvinculada da liberdade e da tolerância; a tolerância independente da humanidade, da igualdade e da liberdade; e assim por diante.

As reflexões desenvolvidas apóiam-se em conhecimentos teorizados por pensadores clássicos e contemporâneos das Ciências Humanas e em entrevistas realizadas no segundo semestre de 2009 com 12 professores de Sociologia - sete

\footnotetext{
${ }^{2}$ A DUDH foi aprovada em assembléia geral da ONU em 10 de dezembro de 1948. Foram 48 votos a favor, nenhum voto contra e oito abstenções da África do Sul, Arábia Saudita, Bielorússia, Iugoslávia, Polônia, Tchecoslováquia, Ucrânia e URSS.
} 
homens e cinco mulheres - de 10 escolas públicas de nível médio: quatro do Distrito Federal e seis de Uberlândia. Nesta última localidade, a disciplina foi incluída no vestibular da Universidade Federal desde 1997, com provas específicas nas $1^{\mathrm{a}} \mathrm{e} 2^{\mathrm{a}}$ fases, com o mesmo número de questões e valor equivalente aos demais conteúdos. Na capital do País, passou a fazer parte do conteúdo básico do currículo desde 2000, com carga horária semanal de duas horas aulas, nas três séries do Ensino Médio. Os depoimentos aqui registrados não são apenas ilustrativos; são evidências da atualidade e das possibilidades de inserção da DUDH na bibliografia da disciplina Sociologia nesse nível de ensino.

\section{O APRENDIZADO DA HUMANIZAÇÃO}

Para se iniciar a reflexão é interessante recorrer a Antônio Cândido que definiu humanização como

0 processo que confirma no homem aqueles traços que reputamos essenciais, como o exercício da reflexão, a aquisição do saber, a boa disposição para com 0 próximo, o afinamento das emoções, a capacidade de penetrar nos problemas da vida, o senso da beleza, a percepção da complexidade do mundo e dos seres, o cultivo do humor (CANDID0, 1995, p. 249).

Como processo, a humanização projeta situações futuras da vida do jovem, ao mesmo tempo em que provoca a reflexão sobre fenômenos sociais imediatos e palpáveis a sua volta, que requerem sensibilidade para que ele se posicione frente a situações cotidianas, como por exemplo, a tolerância em relação ao colega de classe que é homossexual, a preservação do prédio da escola como patrimônio de todos, a valorização das manifestações culturais da comunidade local, o cuidado com as árvores do passeio público, a liberdade em relação à religião ou a opção político partidária do outro.

Rousseau (1712-1778), ao refletir sobre a educação ministrada às crianças de seu tempo, sugere práticas que favoreçam "seus jogos, seus prazeres, seu amável instinto", inclusive. E faz um apelo em favor da humanização:

Homens, sejais humanos, é nosso primeiro dever; e o sejais em relação a todas as situações sociais, a todas as idades, a tudo o que não seja estranho ao homem. Que sabedoria haverá para vós fora da humanidade (ROUSSEAU, 1973, p.61).

A proposta de incluir a DUDH como referência bibliográfica da disciplina Sociologia, ministrada no nível médio, visa compromissar professores e estudantes 
com os princípios que norteiam o documento e que estão sedimentados em valores universais, inquestionáveis e imprescritiveis para toda a humanidade; que estão impressos em diferentes artigos e conteúdos sociológicos e, ao serem trabalhados em sala de aula, estimulam os estudantes a fazerem uma leitura huminazada do mundo em que vivem.

\section{Dignidade}

Conceitualmente, o que se entende quando se fala em dignidade? Dignidade é uma característica inerente a todos os seres humanos; remete a uma postura de vida ética, responsável coerente e libertadora dos homens nas sociedades em que vivem. Um princípio antropológico que define o ser como humano. Entretanto, o conceito de dignidade esbarra na subjetividade, uma vez que é impossível estabelecer limites rígidos, objetivos e definitivos para o que é digno e o que é indigno. Essa imprecisão pode induzir a uma falsa tolerância que se traduz, na prática, em atitudes de desrespeito à pessoa humana.

Para explicar o conceito de dignidade é interessante recorrer a Immanuel Kant (1724-1804), filósofo alemão que viveu no século XVIII, primeiro a considerar o homem um fim em si mesmo devido a sua autonomia como ser racional. Para Kant, a dignidade é uma qualidade inerente aos seres humanos relacionada a tudo aquilo que não tem preço, isto é, que não pode ser substituído por outra coisa do mesmo valor. Homens e coisas se diferenciam: homens têm dignidade, coisas têm preços. Aos homens - únicos que têm dignidade - não se pode atribuir um valor equivalente. Explicado com outras palavras, uma coisa que tem um preço pode ser substituída por outra coisa do mesmo preço. Diferentemente, a dignidade como característica que distingue os seres humanos, está acima de qualquer possibilidade de negociação, de se obter um valor equivalente ou um determinado preço; não tem equivalência com mais nada. É uma qualidade intrínseca aos seres humanos que possuem personalidades individuais, distintas e insubstituíveis. Para Kant, o homem é a medida de valor para todas as coisas; é um fim em si mesmo e não é um meio para se atingir outro fim. A dignidade do homem está vinculada a sua autonomia, que o caracteriza como pessoa (KANT, 1973).

0 conceito de pessoa está atrelado ao de dignidade; ambos são atributos que distinguem os seres humanos de todos os demais; a dignidade é o sustentáculo de todos direitos fundamentais da pessoa humana. "A dignidade de cada homem consiste em ser, essencialmente, uma pessoa, isto é, um ser cujo valor ético é 
superior a todos os demais no mundo" (COMPARAT0, 2010, p. 28). Manifesta-se na ação responsável e livre do ser humano.

Os Direitos Humanos estão entrelaçados a noção de "dignidade dos seres humanos" (RABENHORST, 2009, p. 5), ou seja, são direitos que cada um de nós possui pela própria condição humana. "A idéia de dignidade humana como fundamento dos direitos humanos" consagra o valor que atribuímos aos seres humanos em função das nossas crenças sobre o modo como devem ser tratados: "os homens precisam ser reconhecidos como titulares de direitos básicos" e a dignidade se inclui no rol desses direitos (RABENHORST, 2009, p. 7).

0 Art. VI da DUDH reforça e expande a universalidade desse reconhecimento ao afirmar que "todo ser humano tem o direito de ser, em todos os lugares, reconhecido como pessoa perante a lei." Ser pessoa reclama um tratamento diverso, no sentido positivo do termo, uma vez que estabelece uma comparação entre seres vivos e reconhece o ser humano como de "natureza eticamente responsável” (BENEVIDES, 2007, p.336). Para a Maria Victória Benevides, essa é uma proposição revolucionária, porque concebe o ser humano como fonte de todos os direitos, rompendo com as barreiras territoriais (BENEVIDES, 2007, p. 336).

A proposta é trabalhar o ensino de Sociologia associado à construção de "uma cultura de respeito à dignidade da pessoa humana" (BENEVIDES, 2007, p. 346). A dignidade, como característica de toda pessoa humana, não aceita exclusão de natureza alguma; pressupõe a aprendizagem do respeito ao ser humano, a promoção da cooperação e da tolerância como necessárias à convivência entre as pessoas. Transformar a sala de aula em um espaço estratégico para o cultivo de uma postura ética e capaz de influenciar o comportamento de professores e estudantes, o modo como se relacionam, se reconhecem e autoconhecerem como pessoas dignas.

\section{IGUALDADE}

0 Artigo I da DUDH, ao proclamar que "todos os seres humanos nascem livres e iguais em dignidade e direitos", anuncia aquela que será uma das condutas básicas de todo o documento: direitos iguais e inalienáveis a todos os membros da família humana, entre homens e mulheres. É uma relação de igualdade que se estabelece de pessoa a pessoa, de grupo a grupo. Contudo, o conceito de igualdade entre seres humanos requer um complemento básico que é, justamente, a 
comparação com aquele que lhe conferiu a propriedade de ser igual, e só pode ser concebido se essa comparação é estabelecida. Considerar um grupo humano igual ao outro requer a especificação das características que os igualam. Podem ser iguais quanto ao físico, nacionalidade, idade, rendimentos, necessidades... Considerá-los desiguais, no entanto, implica em hierarquizá-los, em estabelecer padrões para classificá-los.

A DUDH, em seu Preâmbulo e em diferentes artigos, reforça a igualdade de direitos entre os seres humanos. Contudo, a análise do conceito em sala de aula exige atenção para a noção de diferença. Desigual não é o mesmo que diferente e ser diferente não é o mesmo que ser desigual. Homens e mulheres são diferentes; negros e brancos são diferentes; jovens e idosos são diferentes; "cadeirantes" e pessoa que não tem dificuldade de locomoção são diferentes. São relações horizontais que não devem sugerir que um grupo é superior ou inferior a outro.

A complexidade que envolve as noções de igualdade, desigualdade e diferença há muito tem se tornado objeto de discussão. Aristóteles utilizava 0 princípio da igualdade, para tratar igualmente os iguais e desigualmente os desiguais e, assim, propor tratamento desigual aos vários setores da sociedade ateniense: cidadãos, escravos, mulheres, estrangeiros.

Rousseau, a refletir sobre a desigualdade entre os homens, alerta sobre 0 "erro comum" dos teóricos que o antecederam e se referiram ao "homem selvagem enquanto retratavam o homem civilizado" (CHÂTELET, 1985, p.71). Identifica, originariamente, dois tipos de desigualdade: natural ou física, que não the interessa analisar, e moral ou política, que não se estabelece naturalmente e sim com o consentimento humano. Esse segundo tipo, que ele vai chamar de desigualdade moral ou política, não é natural. Para Rousseau, igualdade e liberdade andam juntas e precisam ser preservadas: não há liberdade se não existe igualdade. 0 Contrato Social, sua obra mais importante escrita em 1762, defende que os homens são iguais no estado natural da vida selvagem. Tornam-se desiguais à medida que experimentam a civilização.

Karl Marx (1818-1883), ao analisar o processo de transição da sociedade capitalista para a sociedade comunista, principalmente no que se refere ao trabalho como "padrão igual", a partir de sua duração e intensidade, afirma: "0 direito igual é um direito desigual para trabalho desigual. Não reconhece diferenças de classe, porque cada um é apenas um trabalhador como todos os outros; mas reconhece tacitamente dotes individuais desiguais, e assim reconhece 
a capacidade de produção como privilégio natural" (MARX, 1973, p. 361). Para Marx, o "direito igual" na sociedade capitalista é o "direito burguês". E explica:

Pela sua própria natureza, o direito apenas pode consistir na aplicação de um padrão igual; mas indivíduos desiguais (e não seriam indivíduos diferentes se não fossem desiguais) apenas são susceptíveis de avaliação por meio de um padrão igual se forem considerados apenas como trabalhadores e se nada mais for neles levado em conta, se tudo o mais for ignorado. [...] Assim, com uma produção igual, e conseqüentemente, uma participação igual no fundo social de consumo, um receberá de facto mais do que o outro, um será mais rico do que o outro, e por aí a fora. Para evitar todos esses defeitos, o direito, em vez de ser igual, terá de ser desigual" (MARX, 1973, p. 361).

Rui Barbosa (1849 - 1923) também se preocupou em escrever sobre 0 tema, a partir do que chamou de "A regra da igualdade" e que consiste em "quinhoar desigualmente aos desiguais, na medida em que se desigualam." Para ele, na "desigualdade social, proporcionada à desigualdade natural, é que se acha a verdadeira lei da igualdade. [...] Tratar com desigualdade a iguais, ou a desiguais com igualdade, seria desigualdade flagrante, e não igualdade real" (BARBOSA, 2010, p. 3).

Boaventura de Souza Santos, em poucas palavras, sintetiza essa questão ao defender o multiculturalismo progressista, que pressupõe que o principio da igualdade seja vivenciado em sintonia com 0 reconhecimento da diferença. 0 sociólogo afirma categoricamente: "Temos o direito de ser iguais quando a diferença nos inferioriza; temos o direito de ser diferentes quando a igualdade nos descaracteriza" (SANTOS, 2009, p. 18).

A igualdade, como parte do programa de Sociologia ou mesmo como conteúdo interdisciplinar, foi evidenciada nas entrevistas com docentes do ensino médio, quando perguntados sobre a possibilidade de selecionarem um único artigo da Declaração para se trabalhar em sala de aula. A diversidade dos assuntos relacionados nas duas respostas abaixo mostra que a DUDH pode contribuir efetivamente com o ensino da disciplina:

Eu trabalharia com o $1^{0}$ ano. Através do $1^{0}$ eu posso trabalhar relações de gênero, eu posso trabalhar o próprio item trabalho. Se todos nós somos iguais, somos livres. Será que nós somos realmente livres? 0 trabalho, de repente, não é aquilo que eu gosto, mas estou resistindo. 0 que significa a liberdade? Onde é que fica a igualdade? (Professor I, Uberlândia - MG).

Eu selecionaria a questão da igualdade; a igualdade social. Por que? A gente tenta trabalhar a questão, por exemplo, do etnocentrismo, essa visão 
preconceituosa e respeitar, por exemplo, a desigualdade, o outro. E aí, nessa visão da Declaração eu acho muito importante. E o ser humano tem que ser respeitado pelo fato que ele é ser humano, independente de classe social" (Professora E, Taguatinga - DF).

Na DUDH, a igualdade está diretamente vinculada à liberdade de ser, de pensar e de se posicionar de modo diverso. Entre tantos outros, o Artigo XVIII expressa essa prerrogativa ao afirmar que "toda pessoa tem o direito à liberdade de pensamento, de consciência e de religião"(BRASIL, 2008, p. 9). A liberdade insere-se, então, como condição necessária para que a igualdade se estabeleça. Igualdade e liberdade são direitos humanos que se complementam, não existem isoladamente na vida social.

\section{LIBERDADE}

Como conceber a liberdade um direito dos seres humanos? Responder com os olhos voltados para os clássicos das Ciências Humanas, certamente, tanto esclarece como instiga novos questionamentos. A concordância com a afirmativa de que a liberdade é um dos direitos humanos, não implica a aceitação dos argumentos que a constroem.

John Locke (1632-1704), um dos representantes do liberalismo moderno, defende a idéia de que o homem é "livre por natureza" e somente a partir do próprio consentimento poderá ser submetido ao poder de outro homem. Para ele, liberdade e igualdade são condições que os seres humanos desfrutam quando estão em estado de natureza; que aparecem entrelaçadas; se realizam na dependência uma da outra; que só se efetivam se vinculadas. Nesse estado, é possível desfrutar de liberdade para agir e dispor do que possui. Para ele, liberdade e propriedade não se dissociam. Os homens só podem ser concebidos como iguais se, também, concebidos como livres para agir, sem depender ou pedir autorização a outro homem.

Em Kant, a idéia de liberdade é formulada, inicialmente, pela razão; racionalmente, ele reduziu a liberdade ao que chamou de direitos inatos (BOBBI0, 1992, p. 17). É ela que dá condições ao individuo de usufruir dos demais direitos; não há direito a propriedade e a dignidade se não há liberdade. Porém, ser livre, para 0 filósofo, não é a faculdade natural de escolher, não é o livre arbítrio. 0 individuo tem liberdade quando age obedecendo as leis morais, como sujeito autônomo que impõe a si mesmo, racionalmente, leis que dependem só dele. 
Jean-Jacques Rousseau foi um dos filósofos que inspirou o documento francês da Declaração dos Direitos do Homem e do Cidadão. Defendeu a idéia de que o ser humano se define e se concretiza essencialmente pela liberdade. É ela que diferencia a natureza humana, que a torna especifica, singular; é um dos princípios que orienta a ação moral e política dos homens: "renunciar a liberdade é renunciar à qualidade de homem, aos direitos da humanidade" (ROUSSEAU, 1978, p.27). É seu intuito fazer com que os homens firmem um pacto legítimo, capaz de lhes trazer de volta a liberdade. Explicado em poucas palavras, os homens, ao verem sua segurança e seus bens ameaçados, firmam um contrato para voltar a ser livres. Contudo, não percebem que as vantagens advindas desse contrato são relativas, provisórias e comprometedoras; a liberdade plena que possuíam, deixa de existir.

0 contrato social de Rousseau não é um contrato entre indivíduos, é um pacto firmado "cada um consigo mesmo e que transforma cada indivíduo em cidadão" (CHATELET, 1985, p. 73). Com ele, o homem perde a liberdade natural e tudo o quanto ele seria capaz de lhe proporcionar; renuncia a suas vontades particulares em favor do interesse comum. Após o pacto, a liberdade plena, que permitia ao homem fazer tudo que queria, deixa de existir. "A dependência à vontade particular constitui o pior dos males, e todo golpe à liberdade individual se resume na sua dominação por outra vontade particular" (1969 apud, SAHD, 2005). Ao refletir sobre sua própria liberdade, Rousseau indigna-se: "não é fazer 0 que eu quero, mas não fazer o que não quero" (1964 apud SAHD, 2005).

No livro Emilio ou Da Educação, publicado em maio de 1762, Rousseau apresenta a liberdade como fundamento filosófico para as práticas que inspiram a apreensão desse direito humano na experiência pedagógica. Defende essa postura ao afirmar: "[...] o maior de todos os bens não é a autoridade e sim a liberdade. 0 homem realmente livre só quer o que pode e só faz o que lhe apraz. Eis minha máxima fundamental" (ROUSSEAU,1973, p. 67). 0 filósofo analisa situações cotidianas específicas dos primeiros dias de vida da criança e, principalmente, do período escolar: "a liberdade que dou a meu aluno o indeniza amplamente dos ligeiros incômodos que o exponho" (ROUSSEAU, 1973, p. 70). E de situações mais amplas, como na carta que escreve ao jovem Emílio:

É em vão que aspiramos a liberdade sob a proteção das leis. As leis! [...] A liberdade não está em nenhuma forma de governo, está no coração do homem livre; ele a carrega por toda parte consigo. 0 homem vil carrega por toda parte a escravidão (ROUSSEAU, 1973, p. 560). 
Para Marx, o significado de liberdade no capitalismo, contraditoriamente, está vinculado ao trabalhador que aparece como "homem livre" para vender sua força de trabalho em troca de um salário, diferente do servo medieval, submisso ao senhor feudal. Será, justamente, esse tipo de liberdade que irá destituir o trabalhador de sua humanidade. Em suas palavras, "A humanidade adquire domínio sobre a natureza, mas ao mesmo tempo o homem se converte em escravo dos homens e de sua própria infâmia" (MARX, p. 40, 1984). Para ele, liberdade praticada no capitalismo resumia-se em direitos individualizados:

0 direito do homem à liberdade não se baseia na união do homem com 0 homem, mas na separação entre homens... 0 direito à propriedade é 0 direito de o homem desfrutar de suas posses e delas disporem arbitrariamente, sem consideração com outros homens, independentemente da sociedade: é o direito ao egoísmo. É essa primeira liberdade individual, combinada com sua posterior aplicação, que forma a base de sociedade civil. Ela leva os homens a ver nos outros homens, não a realização, mas a limitação de sua própria liberdade (MACLELLAN, 1993, p. 40).

Na obra de Marx, são as condições materiais de existência que irão determinar os direitos do homem no capitalismo; a libertação do homem depende do fim das necessidades de classe, ou seja, só com o fim das classes sociais será possível a humanidade dos homens, que é a liberdade em sentido pleno. Decorrente do próprio conceito de liberdade, e em condição oposta, Marx concebe o estado de alienação, "que é a negativa da especificidade humana, como enfatizou Feuerbach" (COMPARATO, 2010, p. 24), e que se caracteriza pela incapacidade de o homem exercer sua liberdade na sociedade capitalista. A superação da alienação seria possível com a sociedade comunista, quando a liberdade torna-se um direito todos e não privilégio dos donos dos meios de produção, como ocorre no capitalismo, cujos direitos do homem são os direitos burgueses e não direitos que todos desfrutam igualmente. Nas palavras do pensador,

A emancipação humana só será plena quando o homem real e individual tiver em si o cidadão abstrato; quando como homem individual, na sua vida empírica, no trabalho e nas suas relações individuais, se tiver tornado um ser genérico; e quando tiver reconhecido e organizado as suas próprias forças como forças sociais, de maneira a nunca mais separar de si esta força social como força política (MARX, 1964, p. 40).

No último parágrafo do Manifesto, Marx e Engels projetam a liberdade como resultado da revolução comunista e afirmam: "Que a classe operária nada 
perderá com ela, a não ser a sua prisão. Mas terão um mundo a conquistar. Proletários de todos os países, uni-vos!" (MARX e ENGELS, 1986, p. 45).

Relacionado diretamente a situação de liberdade, a análise que Weber faz da cidade medieval é motivadora para se refletir sobre o tema no, então, capitalismo nascente. A célebre frase "o ar da cidade é libertador" sintetiza as possibilidades vislumbradas por esse novo espaço; focaliza a cidade do final da idade média como um espaço que vai da servidão à liberdade, embalada pelo lucro monetário (WEBER, 1999). Concebida pelo sociólogo como um "estabelecimento de mercado", a cidade representa a liberdade do servo em relação ao senhor feudal, livre da sujeição, libertado da servidão. Contraditoriamente, essa mesma liberdade que a cidade proporcionava e que impulsionava o processo de urbanização européia, não será suficientemente capaz de absorver toda a população de servos originária dos feudos.

Na DUDH a liberdade é proclamada no Preâmbulo e em diferentes artigos como condição para o reconhecimento da "dignidade inerente a todos os membros da família humana e seus direitos iguais e inalienáveis"; o fundamento que sustenta o respeito aos direitos de todos e de cada um e promove o "progresso social" e "melhores condições de vida". Nas falas dos professores entrevistados, 0 direito humano liberdade foi exposto em diferentes possibilidades para o trabalho docente. Foram semelhantes às considerações relativas à inserção desse direito como conteúdo de Sociologia:

Desde o conceito de liberdade nós podemos englobar todos os outros temas que existem na Declaração. Você vai trabalhar o etnocentrismo, com a questão da liberdade, a moral, dá pra trabalhar toda a estrutura social. Que liberdade é possível, o que é liberdade dentro de uma estrutura social, que liberdade eu estou sendo tolhido, dá pra fazer uma análise dos direitos humanos universais a partir deste tema. A questão do racismo dá pra ser abordada a partir daí (Professor K - Taguatinga - DF).

Direito a vida, direito à liberdade, a liberdade, a vida. Se for analisar, pra mim é fundamental o direito à vida. Ao mesmo tempo, tem alguns que acham que a liberdade é muito mais importante, se você não tiver liberdade você não tem vida. São momentos de valor. Aí você pega tudo, direito a saúde, direito a educação, tudo que a gente vive, está lá na Constituição, por exemplo (Professor C - Uberlândia- MG).

A liberdade pode assumir um significado palpável na escola como, por exemplo, o momento em que a aula termina e os estudantes voltam paras suas 
casas; ou, inversamente, quando algum(a) colega é detido(a) pela policia. Em tais situações, fica fácil compreender o que é liberdade. Etnocentrismo, racismo, preconceito, o próprio direito a Educação passam pelo viés da liberdade, que assume conteúdo disciplinar no programa de Sociologia do Ensino Médio.

\section{RESPEITO}

0 texto da DUDH, suporte material dessa discussão, cita, logo no Preâmbulo, o ensino e a educação como responsaveis "por promover o respeito a esses direitos e liberdades" (BRASIL, 2008, p 4). A ação de respeitar, concebida como "tratar com reverência ou acatamento; venerar, honrar" (FERREIRA, 1986, p.1495) exige materialidade para ser praticada em sala de aula. Partindo dessa constatação, como pensar a prática do respeito, a partir do conteúdo programático de Sociologia no nível médio?

A rigor, a ação de respeitar nao tem limites, quando o objetivo é definir "a quem" ou "o que" se deve respeitar. Por outro lado, a pergunta inversa, quem ou o que nao merece respeito, utrapassa os limites da ação e não responde a afirmação contrária de que esse ou aquele não deve ser respeitado.

Os estudantes do ensino médio, destinatários e protagonistas do processo educativo, ocupam o centro da cena escolar tornando-se referência para a promoção dos direitos e liberdades propostas na DUDH. A proposta para o trabalho acadêmico em sala de aula é de se iniciar com questões bem simples, próximas do cotidiano dos estudantes, capazes de materializar 0 respeito aos direitos e as liberdades expressos na DUDH, para, em seguida, estendê-las a outras esferas da vida social. 0 trecho da entrevista com uma professora de Uberlândia é ilustrativo da materialidade que se pode imprimir a concepção de respeito, nas aulas de Sociologia:

Em 2008, teve um caso bem legal, uma sala de $3^{\circ}$ ano muito agitado, tinha um menino que era homossexual, ele falou pra mim: "professora, este tema eu quero". Aí eu falei: "tá bom Tiago, mas esse tema você vai ter que fundamentar. Não é bandeira, não é manifestação, é a Sociologia. E ele foi, fez a pesquisa sobre a história da homossexualidade no mundo, sobre as pessoas que já morreram por isso. Os colegas ficaram parados ouvindo ele falar. Tem que respeitar. Eu encontro com ele na rua ele fala: "minha professora!" (Professora D, Uberlândia-MG).

A concepção de respeito balizou o preparo do tema pelo estudante, quando ele se propôs a trabalhar o homossexualismo, na esteira dos Movimentos Sociais: 
materializou-se como postura acadêmica frente a si mesmo, à professora e seus colegas de sala. A professora, fundamental para essa materialização, recorreu a Sociologia como esteio teórico da atividade: 0 que possibilitou ao estudante apresentar e discutir uma questão que faz parte de sua vida particular, mas que também é fonte de preconceito, discriminação e desrespeito coletivos. Ainda que "0 respeito aos direitos e liberdades" tenham sido postos a prova, a DUDH não foi cogitada, como princípio norteador ou pano de fundo para o tratamento do assunto.

Especificamente, neste caso, como poderia a DUDH contribuir para 0 desenvolvimento da temática? Pra começo de conversa, é preciso deixar claro que "os direitos humanos estão fundados na relação de pessoa a pessoa, relação essa de igualdade" (CANIVEZ, 1991, p.89). Explicando melhor, os direitos humanos, como direitos dos outros são, também, direitos de cada um, individualmente, e de todos, coletivamente. 0 direito à sexualidade, como condição de liberdade, manifestada no estudante não pode ser proclamada de forma independente, individual. Requer o conhecimento próprio e do outro, que por sua vez, também é detentor de tais direitos. Respeitar o outro é respeitar a si mesmo, enquanto ato e efeito praticado em sala de aula.

Entre os trinta artigos da DUDH, há abrigo ao respeito à homossexualidade? Diretamente, não. 0 próprio caráter histórico do documento, escrito em 1948, justifica essa ausência e reclama a necessidade de uma atualização da leitura. 0 direito e a liberdade de ser homossexual se inscrevem no "direito à vida, à liberdade, à segurança pessoal" (Art. III) e pela especificidade da questão, à "proteção contra qualquer discriminação" (Art. VII). Do lado inverso do Art. XII, que determina "ninguém sofrerá interferências em sua vida privada, nem ataque a sua honra e reputação" (BRASIL, 2008, p.9) está a homofobia, uma violência de gênero ao ser praticada contra homossexuais e que se caracteriza pela agressividade, medo, desconfiança, hostilidade, enfim, manifestações preconceituosas e discriminatórias que comprometem a liberdade do outro. Ao trabalhar esse conteúdo no interior dos Movimentos Sociais, é possível trazer a discussão para a esfera coletiva, uma vez que as manifestações de homofobia, marcadas pelo desrespeito aos homossexuais, não são fenômenos individuais e isolados; são coletivos.

\section{TolerÂNCIA}

Na DUDH a tolerância aparece não como o direito de ser tolerante ou de ser tolerado, mas como conseqüência de uma situação em que os direitos humanos 
são experimentados e praticados. Analisada de modo amplo e generalizado, a tolerância está vinculada à diversidade cultural, à democracia e à paz entre as nações.

A Declaração de Princípios Sobre a Tolerância, aprovada pela Conferência Geral da UNESCO, na 28 reunião, em 16 de novembro de 1995, em Paris, assume a dianteira na promoção da tolerância não apenas como principio relevante mas, igualmente, uma condição necessária para a paz e para o progresso econômico e social de todos os povos. Na leitura deste documento, vale a pena ressaltar os objetivos referentes à preservação das "gerações vindouras do flagelo da guerra" e da tolerância como prática para uma convivência pacífica. Para este estudo, o destaque vai para os trechos abaixo, devido a ênfase que é conferida ao reconhecimento e à prática de aceitação do outro:

A tolerância é, antes de tudo, uma atitude ativa fundada no reconhecimento dos direitos universais da pessoa humana e das liberdades fundamentais do outro. [...] A prática da tolerância significa que toda pessoa tem a livre escolha de suas convicções e aceita que o outro desfrute da mesma liberdade. Significa aceitar o fato de que os seres humanos, que se caracterizam naturalmente pela diversidade de seu aspecto físico, de sua situação, de seu modo de expressar-se, de seus comportamentos e de seus valores, têm o direito de viver em paz e de ser tais como são. Significa também que ninguém deve impor suas opiniões a outrem (Declaração de Princípios Sobre a Tolerância, 1995, p. 2).

Para esta análise, importa a tolerância em seu aspecto "miúdo", que diz respeito ao dia a dia do ambiente escolar e cuja ausência pode ter consequiências drásticas para todos que nele convivem. A escola, como lócus propício ao aprendizado da tolerância, é também um espaço que possibilita experimentar a prática inversa desse conteúdo, nas inúmeras situações em que ser tolerante tornase fundamental para a convivência coletiva.

0 conteúdo da Sociologia no nível médio, por mais acadêmico e sistematizado que seja, precisa estar "antenado" às situações em que a violação dos direitos humanos coloca em risco a humanização da educação, de uma forma geral, principalmente quando acontece no ambiente escolar e é admitida como natural e esperada. A análise de um dos professores pesquisados é ilustrativa de como a disciplina pode contribuir para o aprendizado da tolerância:

Eu acho que eles têm que ter uma relevância teórica, mas, sobretudo, uma aproximação da vivência dos alunos. É claro que eles precisam usar os conteúdos e, aí sim, procurar os conteúdos que me ajudem a explicar melhor 
essa realidade para os alunos. Perceber melhor essa realidade, que tipo de profissional, que intolerância está sendo praticada. Ela foi expulsa e a ação dos alunos foi considerada proteção a ética e a moral e aos bons costumes daquela universidade. Eu tenho que deixar os alunos perceberem de outra maneira a mesma realidade (Professor $\mathrm{K}$ - Taguatinga - DF).

A resposta do professor faz referência ao episódio de expulsão da estudante de uma universidade paulista, nacionalmente conhecido. Como ele, inúmeros casos de intolerância são praticados diariamente nas escolas brasileiras sem provocar qualquer tipo de estranhamento, condição necessária para uma leitura sociológica do mundo. Desde o bulling às humilhações recíprocas entre docentes e estudantes, o espaço escolar é um campo minado de intolerância.

\section{PARA CONCluir}

0 texto da DUDH, tomado como material didático de apoio para as atividades da disciplina Sociologia no ensino médio, propicia uma relação pedagógica concreta com a realidade, instigando a reflexão sobre situações sociais que exigem uma postura coerente com a condição humana. Adiscussão sociológica de cada uma das concepções aqui elencadas estimula a reflexão sobre uma série de questões que não necessariamente estão expressas naquele documento, mas que são vivenciadas diariamente pelos estudantes.

Para este estudo interessa, prioritariamente, a sala de aula do ensino médio e 0 ambiente escolar como um todo, o que não deve se tornar uma limitação para a análise sociológica dos direitos humanos de um modo geral. Não há nenhuma pretensão que a reflexão ocorra de modo espontâneo; pelo contrário, a Sociologia está habilitada a discutir cientificamente a DUDH em caráter disciplinar, a partir de unidades do programa que tratem do respeito à diversidade, das diferenças socioculturais, da igualdade entre os diferentes, das questões de gênero, desigualdades econômicas, caracterizações multiculturais.

A intenção é trabalhar os significados sociológicos da humanização, dignidade, igualdade, liberdade, respeito e tolerância como conteúdos e como postura de vida: conhecimentos que mantém relação estreita com a disciplina e devem ser desenvolvidos com o mesmo cuidado teórico e conceitual dos demais, uma vez que remetem a práticas experimentadas diariamente pelos estudantes na escola e fora dela. 


\section{REFERÊNCIAS}

BARBOSA, Rui. Oração aos moços. Outubro, 2000. Disponível em <http://www. casaruibarbosa.gov.br/dados/DOC/artigos/rui_barbosa/FCRB_RuiBarbosa_ Oracao_aos_mocos.pdf >. Acesso em 20 de março de 2010.

BENEVIDES, Maria Victoria. Cidadania e Direitos Humanos. Disponível em $<$ http://www.iea.usp.br/textos/benevidescidadaniaedireitoshumanos.pdf> Acesso em 25 de março de 2010.

BENEVIDES, Maria Victoria. Direitos humanos: desafios para o século XXI. In: SILVEIRA, R. M. Godoy (org.) Educação em Direitos Humanos: fundamentos teórico-metodológicos. João Pessoa: Editora Universitária, 2007.

BOBBI0, Norberto. A era dos direitos. Rio de Janeiro: Editora Campus, 1992.

BRASIL. Constituição Brasileira 1988. Rio de Janeiro: Forense Universitária, 1988.

BRASIL. Declaração Universal dos Direitos Humanos. Secretaria Especial da Presidência da República. 2008.

CÂNDID0, Antônio. Vários escritos. São Paulo. Livraria Duas Cidades. 1995.

CANIVEZ, Patrice. Educar o Cidadão? Campinas: Papirus, 1991.

CHÂTELET, F., DUHAMEL, 0 e PISIER-KOUCHNER, E. História das idéias políticas. Rio de Janeiro: Jorge Zahar Editor, 1985.

COMPARATO, Fábio K. A afirmação histórica dos direitos humanos. São Paulo: Saraiva, 2001.

COMPARAT0, Fábio K. Fundamento dos direitos humanos. Instituto de Estudos Avançados da USP. Disponível em <www.iea.usp.br/iea/textos/ comparatofundamento.pdf. > Acesso em 02 de janeiro de 2010.

FERREIRA, Aurélio Buarque de Holanda. Novo Dicionário da Língua Portuguesa. Rio de Janeiro: Editora Nova Fronteira, 1986.

GAARDER, Jostein. O mundo de Sofia. Romance da História da Filosofia. Tradução de João Azenha Jr. São Paulo: Companhia das Letras, 1996, p. 364.

KANT, Immanuel. Fundamentação da Metafísica dos Costumes, SP, Editora Abril, Col. Os Pensadores, 1973.MACLELLAN, David. As idéias de Marx. São Paulo: Cultrix, 1975.

MARX, Karl. As revoluções de 1848 e o proletariado. In: RIAZANOV, D. (Org.). Marx, o homem, o pensador, o revolucionário. São Paulo, Global Editora, 1884. 
MARX, Karl. A Questão Judaica. In: Manuscritos-Económico Filosóficos. Lisboa: Edições 70, 1964. p. 40.

MARX, Karl. e ENGELS, Friedrich. Manifesto do Partido Comunista. São Paulo: Editora Global, 1986.

RABENHORST, Eduardo R. 0 que são os direitos humanos? Disponível em <www. redhbrasil.net/documentos/.../1.o_q_sao_dh_eduardo.pdf> Acesso em 12 de dezembro de 2009.

ROUSSEAU, Jean-Jacques. Do Contrato Social ou Princípios do Direito Político. Livro primeiro. Tradução de Lourdes Santos Machado. São Paulo: Abril Cultural, 1978. p. 27 ROUSSEAU, Jean-Jacques. Emilio ou Da Educação. Tradução de Sérgio Milliet. 2ed. São Paulo: Difusão Européia do Livro, 1973.

SAHD, L. F. N. de Andrade e Silva. A Noção de Liberdade no Emílio de Rousseau. Trans/Form/Ação [online]. Vol.28, n.1, Marília, 2005, p 109-118. Acesso em 29 de março de 2010.

SANTOS, Boaventura S. Direitos Humanos: o desafio da interculturalidade. BRASIL, Revista Direitos Humanos. N. 2. Junho 2009, p. 18.

UNESCO. Declaração de Princípios Sobre a Tolerância. Paris, 16 de Novembro de 1995.

WEBER, Max. Economia e Sociedade. Vol.2 Fundamentos da Sociologia Compreensiva. Brasília: Editora UnB, 1999. 